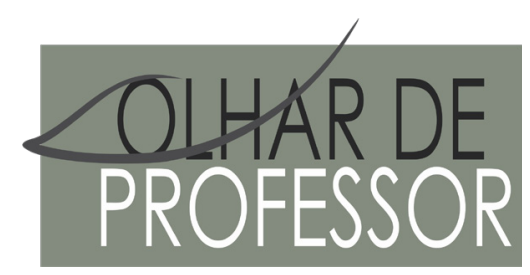

DOI: 10.5212/OLHARPROFR.v.22.0017

\title{
ESTÁGIO DE EDUCAÇ̃̃o INFANTLL: AS EXPERIÊNCIAS FORMATIVAS DOS DISCENTES DO CURSO DE PEDAGOGIA DA UFRB
}

\author{
INTERNSHIP IN CHILD EDUCATION: THE STUDENTS' EXPERIENCE TRAINING FROM UFRB PEDAGOGY \\ COURSE
}

\author{
PASANTía dE EDUCACIÓN INFANTLL: LAS EXPERIENCIAS FORMATIVAS DE LOS ALUMNOS DE LA \\ GRADUACION DE PEDAGOGía DE LA UFRB
}

\author{
KARINA DE OLIVERA SANTOS CORDEIRO* \\ FERNANDA SOARES PEDREIRA ANDRADE CRUZ $Z^{\text {t* }}$
}

\begin{abstract}
Resumo: Este artigo apresenta relatos das experiências de estágio na Educação Infantil do curso de Licenciatura em Pedagogia da Universidade Federal do Recôncavo da Bahia (UFRB). O objetivo desse texto é socializar como as experiências formativas de cinco discentes do curso supracitado em atividades de estágio tem proporcionado uma reflexão sobre a construção de saberes para a futura prática docente. Como metodologia, utilizou-se da elaboração de memoriais formativos que expressaram criticamente o processo de iniciação à docência na primeira etapa da Educação Básica. Esse processo contribuiu para reflexões práticas sobre as principais concepções de infância e de atendimento às crianças, à luz das diversas fases históricas e tendências pedagógicas da Educação Infantil.
\end{abstract}

Palavras Chave: Estágio. Experiências formativas. Memoriais.

\begin{abstract}
This article presents reports of the internship experiences in Early Childhood Education, from the Pedagogy course of the Federal University Recôncavo da Bahia (UFRB). The purpose of the text is to socialize how the formative experiences of 05 undergraduate students mentioned in internship activities have provided an analysis on the knowledge construction for future teaching practice. As methodology we used the elaboration of formative memorials that expressed critically the process of initiation to teaching in the first stage of Basic Education. This process contributed to reflections on the main conceptions of childhood and assistance to children, the idea of the different historic phases and pedagogical tendencies of Child Education.
\end{abstract}

Keywords: Internship. Formative experiences. Memorials.

Resumen: Este artículo presenta relatos de las experiencias de la pasantía en la Educación Infantil de la graduación en Pedagogía de la Universidad Federal del Recóncavo de la Bahia (UFRB). El objetivo de ese texto es socializar cómo las experiencias formativas de cinco alumnos de la graduación citada arriba en actividades de pasantía tienen proporcionado una reflexión acerca de la construcción de saberes para la futura práctica docente. Como metodología, se utilizó de la elaboración de memoriales formativos que expresaron críticamente el proceso de iniciación a la docencia en la primera etapa de la Educación Primaria. Ese proceso contribuyó para reflexiones prácticas acerca las principales concepciones de infancia y atendimiento a los niños, a la luz de las distintas etapas históricas y tendencias pedagógicas de la Educación Infantil.

Palabras-clave: Pasantía. Experiencias formativas. Memoriales.

\footnotetext{
*Doutora em Educação. Professora Adjunta da UFRB. koscordeiro@ufrb.edu.br

** Graduanda em Pedagogia. Bolsista PIBIC da UFRB. nanda.03@outlook.com
} 


\section{INTRODUÇÃO}

Este trabalho apresenta resultados de uma pesquisa realizada com cinco discentes que fizeram o estágio no semestre acadêmico 2018.2, no curso de Pedagogia do Centro de Formação de Professores (CFP) da Universidade Federal do Recôncavo da Bahia (UFRB). O componente de estágio é denominado de "Ensino e Aprendizagem da Educação Infantil e Alfabetização" tem uma carga horaria de 85 horas e ocorre nas instituições públicas de Educação Infantil do município de Amargosa - Bahia.

O curso de Licenciatura em Pedagogia na UFRB teve o seu início em 2006. Naquela época, o curso começou suas atividades em um prédio disponibilizado pela Secretaria Municipal de Educação. Atualmente, encontra-se funcionando em um prédio próprio com 8 turmas de Pedagogia nos turnos matutino e noturno e já formou ao longo desse período aproximadamente 350 discentes.

Por ser uma Universidade criada a partir do projeto de expansão do ensino superior, consideramos que apresentar os resultados desse estudo pode colaborar para fortalecer o trabalho que se desenvolve para a formação dos futuros professores da Educação Infantil do município e cidades circunvizinhas, além de contribuir com outros cursos de Instituições de Ensino Superior (IES), a partir de nossas experiências formativas.

O estágio na Educação Infantil configura-se como uma importante oportunidade para os discentes que estão na construção de saberes necessários à docência. Esta etapa de estágio ganha respaldo, uma vez que aproxima os discentes da Licenciatura com a Educação Básica desde o início do curso.

A fundamentação teórica desse estudo baseia-se nos autores Rocha, Girardi e Buss-Simão (2014), Barbosa (2009), Rocha e Ostetto (2008), dentre outros. Para este artigo foram analisados cinco memoriais formativos. A autorização para divulgação e análise desse material se deu por meio da assinatura do Termo de Consentimento Livre e Esclarecido (TCLE). A partir desse consentimento foi disponibilizado os memoriais digitalizados para procedermos à análise. As categorias de análise que emergiram durante a leitura e categorização ficaram com a seguinte configuração: 1) Reflexão sobre as experiências infantis; 2) Aspectos formativos na universidade; 3) Processo formativo no estágio e 4) Reflexões sobre o estágio.

O texto encontra-se organizado em três partes, na primeira realiza-se uma breve fundamentação teórica sobre as funções da Educação Infantil. Posteriormente, debate-se os estudos sobre o estágio na Educação Infantil e, por fim, articula as pesquisas contemporâneas sobre o estágio e a formação de professores. A segunda parte do texto discute a metodologia utilizada nessa proposta de investigação, além disso, apresenta como identificamos quem são os sujeitos da pesquisa. Na terceira parte procedem-se às análises das categorias supracitadas.

\section{O ESTÁGIO COMO EXPERIÊNCIA SOCIAL, POLÍTICA E PEDAGÓGICA}

Acerca da especificidade da Educação Infantil, Barbosa (2009) apresenta três funções indissociáveis, quais sejam: a primeira é a função social em que consiste em acolher, com práticas de educação e cuidados, as crianças de 0 a 6 anos em regime de compartilhamento com as famílias. A segunda função é a política, que permite que essas crianças tenham acesso aos direitos constitucionais de acesso à educação. E a terceira função é a pedagógica, que corresponde a um lócus de convivência para a aprendizagem e ampliação dos saberes (BARBOSA, 2009). Desse modo, entende-se que o trabalho na Educação Infantil deve articular essas funções para garantir o desenvolvimento integral das crianças.

De acordo com Barbosa (2009, p. 37), para ser professor da Educação Infantil é necessário que ocorra "uma formação que integre, por um lado, formação cultural, ética e estética nas diferentes linguagens expressivas”. Nesse sentido, faz-se necessário aliar à formação, inicial e/ou continuada, experiências que promovam a construção identitária dos docentes dessa etapa de ensino.

Quando consideramos que só a partir da Lei de Diretrizes e Bases da Educação (LDB) 9394/96, a Educação Infantil passou a fazer parte da Educação Básica, identifica-se que o reconhecimento desta etapa como campo de atuação profissional é recente. O movimento para o fortalecimento e inclusão desses profissionais tem se caracterizado enquanto espaço de luta e de disputa política pelos pesquisadores da 
área, a fim de que a formação dos(as) professores(as) possa atender as demandas das crianças de zero a cinco anos de idade nas instituições de creches e de pré-escolas.

O estágio supervisionado de Educação Infantil nos cursos de Licenciatura em Pedagogia, de acordo com Rocha e Ostetto (2008, p. 108), deve ser uma possibilidade "para as educadoras em formação de exercitar o olhar e experimentar ver além do aparente, na complexa configuração do cotidiano infantil”. As autoras afirmam que o estágio deve ser um momento formativo para as práticas de educação e cuidado com as crianças da Educação Infantil.

O estágio em Educação Infantil, como afirmam as autoras, deve assegurar aos discentes dos cursos de Pedagogia uma dinâmica constante das ações pedagógicas a partir da investigação do universo infantil, uma vez que, não se trata apenas da programação de atividades e da organização das rotinas das crianças (ROCHA; OSTETTO, 2008). Assim, reconhecemos que a formação acadêmica contribui de forma significativa para consolidar, durante a formação inicial, uma investigação implicada com o reconhecimento da cultura infantil e com os direitos sociais das crianças. Desse modo, faz-se necessário realizar articulações entre a universidade e as instituições de Educação Infantil com a proposição de que tais espaços formativos colaborem com a formação inicial desses futuros profissionais que atuarão com as crianças.

No que diz respeito às discussões sobre o estágio nos cursos de formação de professores, utilizamos as construções teóricas formuladas por Pimenta e Lima (2005-2006) em que indicam que o momento do estágio deve se constituir a partir de "um estatuto epistemológico que supera sua tradicional redução à atividade prática instrumental” (Idem, p. 6). De acordo com as autoras, a "contraposição entre teoria e prática não é meramente semântico, pois se traduz em espaços desiguais de poder na estrutura curricular" (Ibidem, p. 7). Deve-se estabelecer com os discentes que o estágio supervisionado precisa ser compreendido como a aproximação da realidade escolar, pois só assim será possível superar a dicotomia entre teoria e prática (PIMENTA; LIMA, 2005-2006).

Para Pimenta e Lima (2010), durante a realização dos estágios os discentes vivenciam, nas instituições parceiras da universidade, saberes, conhecimentos e aprendizagens que garantem informações sobre a realidade escolar. As autoras afirmam que o estágio "é atividade teórica de conhecimentos, fundamentação, diálogo e intervenção da realidade” (PIMENTA; LIMA, 2010, p. 45). Desse modo, o estágio se configura como uma oportunidade para a construção de saberes docentes, a partir de uma prática cotidiana que acolhe as experiências dos diversos espaços de aprendizagens para proporcionar uma ação refletida acerca da prática pedagógica.

Ao discutir o estágio como etapa mobilizadora de aprendizagens e de trocas de saberes, podemos compreendê-lo "como um espaço e tempo curricular que permite o exercício de ampliação do olhar dirigido às crianças e à prática pedagógica, por meio da imersão no cotidiano educativo no encontro com o coletivo" (BUSS-SIMÃO et al, 2014, p. 113).

No que diz respeito à finalidade da Educação Infantil, Silva (2013) afirma que é necessário compartilhar as ações de cuidado e de educação das crianças com as suas respectivas famílias e com a comunidade. Dessa forma, não há espaço para práticas pedagógicas que privilegiem ações sem a participação das crianças. A autora destaca que "é preciso dar conteúdo ao que se entende por professor ou professora de bebês e crianças pequenas" (SILVA, 2013, p. 29). Portanto, a formação inicial destes profissionais deve ser fundamentada nos diversos aspectos do desenvolvimento das crianças e sobre as relações que elas estabelecem umas com as outras e com os adultos.

De acordo com Rocha e Ostetto (2008), "a proposta de registrar a experiência vivida, descrevendo e analisando a complexa trama do cotidiano educativo, com seus fios, laços e nós, tem sido apontada e assumida como essencial para a qualificação da prática pedagógica” (ROCHA; OSTETTO, 2008, p. 13). Assim, ao proporcionar essa reflexão no próprio campo de docência, afirmamos que o estágio aproximou o futuro docente da realidade que ele viverá ao concluir o curso de graduação, permitindo-lhe observar e atuar cotidianamente por meio dos processos de ensino, aprendizagem e desenvolvimento da criança.

A partir dessa experiência, foi possível observar que os discentes puderam compreender, a partir de um olhar implicado com as formulações teóricas estudadas, como ocorrem as reflexões sobre as práticas pedagógicas nas instituições escolares. Por meio dessas vivências, surgiram reflexões que rememoraram 
aspectos da infância dos estagiários, o que permitiu que eles realizassem a contextualização das próprias experiências com questões contemporâneas acerca do direito a uma Educação Infantil pública e de qualidade, bem como, quais os impactos e a importância que essa etapa de ensino tem hoje para as crianças que a frequentam, pois quando se tem registrado tais experiências práticas é possível, posteriormente, fazer uma reflexão (ROCHA; OSTETTO, 2008).

Rocha e Ostetto (2008), indicam ainda a necessidade do registro das experiências de estágio como fontes de reflexão para as próximas ações docentes. Em nossa investigação, utilizamos o registro a partir da escrita do memorial com as reflexões tanto das experiências escolares e extraescolares dos estagiários, bem como a formação desde que ingressaram na universidade até o momento da realização do estágio. Nesse sentido, a autora diz que "ao escrevermos nossa experiência, nosso fazer ganha visibilidade, torna-se documento ao qual podemos retomar para rever o vivido, atribuindo-lhe outros significados e projetando fazeres desejados ou necessários (ROCHA; OSTETTO, 2008, p. 13). Com isso, foi possível compreender, a partir dessa análise, como os estudantes de Pedagogia da UFRB mobilizam os saberes docentes para a ação prática com crianças da Educação Infantil.

É importante compreender que a teoria pode explicar e colaborar para as ações práticas. A teoria traz subsídios para identificar, na prática, os acontecimentos do cotidiano, neste caso, os acontecimentos da Educação Infantil. É preciso compreender que ao se deparar com uma turma de crianças pela primeira vez, os estagiários provavelmente terão dificuldades em lidar com situações práticas. Há quem verbalize que teoria e prática são coisas distintas nessa ação, contudo sabe-se, por meio de estudos e pesquisas acadêmicas, que elas favorecem a práxis pedagógica e são, ao mesmo tempo, indissociáveis.

O estudo das autoras Rocha, Girardi e Buss-Simão (2014), apresenta uma discussão sobre o estágio no curso de Pedagogia da Universidade Federal de Santa Catarina (UFSC) realizada em uma creche de Florianópolis. Desse modo, as autoras utilizaram de cenas cotidianas em que ocorreram interações, seja por meio das brincadeiras ou pela modificação dos espaços e objetos. Além disso, as autoras traçaram uma argumentação teórica sobre a concepção de criança e infância, bem como a importância da Educação Infantil para o desenvolvimento integral das crianças. Discutem, também, acerca dos núcleos do trabalho pedagógico, a saber: linguagem oral e escrita, a linguagem sonora corporal e visual, e as relações com a natureza e a sociedade.

Nesse sentido, o estudo que as autoras realizaram tem indicações como a configuração do tempo e do espaço é modificada a partir das necessidades das crianças que estão na creche. Segundo Rocha, Girardi e Buss-Simão (2014) tem sido importante acompanhar as experiências de estágio na Educação Infantil, pois a possibilidade de aproximação com a realidade escolar dos estagiários com o local de sua futura atuação permite reflexões sobre o ser docente na contemporaneidade. Ao mesmo tempo, elas reconhecem os desafios em ser professoras de bebês, uma vez que o olhar direcionado a esse público deve ser mais atento para compreender as diversas formas comunicativas marcadamente manifestas por expressões não verbais.

Drago e Filho (2018, p. 22), afirmam que "no estágio supervisionado o cotidiano de escolas/espaços de educação da criança pequena tem o papel imprescindível para que o futuro profissional entenda como se materializa essas concepções que emergem do cotidiano escolar”. Nesse sentido, as teorias estudadas previamente colaboram para a compreensão das realidades existentes no espaço da Educação Infantil, futuro campo de atuação docente.

É preciso destacar as universidades e as creches e pré-escolas, instituições públicas municipais em que se realizam os estágios em Educação Infantil, como lugares aprendentes, uma vez que compreendemos, assim como Schaller (2008, p. 69), que "os lugares se constituem e aprendem ao mesmo tempo em que ensinam e constituem os atores que vivem neles". Desse modo, as experiências vivenciadas nesses espaços transformam todos os sujeitos que ali desenvolvem o trabalho pedagógico.

A realização do estágio supervisionado em Educação Infantil nesses “lugares aprendentes”, possibilita a articulação entre a universidade e as instituições da Educação Básica a fim de proporcionar ações que colaborem com a formação dos futuros pedagogos. Como metodologia para a organização do estágio, realizamos vários momentos formativos tanto na universidade, quanto nas creches e pré-escolas, para que as discentes pudessem ter a oportunidade de realizar o diagnóstico escolar com elementos 
teórico-práticos que permitissem a compreensão da importância dos diversos aspectos didáticos para a organização das atividades pedagógicas. Além disso, foi possível conhecer, no interior desses espaços, quais os projetos que estavam sendo desenvolvidos para, assim, colaborarem durante a realização do estágio supervisionado em Educação Infantil.

O estágio tem se apresentado, na perspectiva das discentes, como uma etapa desafiadora no processo formativo, uma vez que elas assumem a responsabilidade de organizar e realizar as atividades pedagógicas das crianças em parceria com os docentes em exercício. É importante destacar que apesar de desafiador, esse momento formativo também tem se constituído como uma etapa singular na definição do objeto de pesquisa e do campo de atuação profissional. Algumas discentes, ao realizarem o estágio supervisionado em Educação Infantil, definem como tema dos Trabalhos de Conclusão de Curso (TCC) questões que emergiram das atividades práticas e ainda dão continuidade aos estudos em formação continuada ou em projetos de extensão na Universidade.

\section{METODOLOGIA}

Tomou-se como base epistemológica para a elaboração desse trabalho, o paradigma emergente de Souza (2008), uma vez que acredita-se que o conhecimento é também científico e social, pois durante a realização desta pesquisa buscou-se a superação entre a fragmentação sujeito e objeto, pesquisador e pesquisado. Assim, os estagiários puderam, em suas narrativas, falar de si mesmo constituindo, essa ação refletida, em um autoconhecimento a partir de saberes práticos elaborados durante o estágio.

Utilizou-se como instrumento para a coleta de dados os memoriais formativos, elaborados como um dos requisitos para o Componente Curricular de estágio denominado "Ensino e Aprendizagem na Educação Infantil e Alfabetização” do Curso de Licenciatura em Pedagogia do CFP/UFRB. Tal componente é ofertado sistematicamente no $3^{\circ}$ semestre do Curso e tem como um dos principais objetivos inserir os discentes na docência na Educação Infantil em instituições públicas municipais de Amargosa - Bahia. Durante a elaboração desse material foi solicitado aos discentes que escrevessem sobre seu processo formativo desde a infância com uma perspectiva crítica, uma vez que a formação no referido curso tem apresentado elementos que contribuem para outros olhares para essa etapa de desenvolvimento.

Apoiou-se nos estudos de Passegi (2010), acerca dos memoriais formativos, pois acredita-se que as experiências individuais e/ou coletivas podem ser descritas a partir da escrita autobiográfica. Além disso, nesses memoriais, os discentes tiveram a oportunidade de narrarem suas trajetórias com as diversas aprendizagens. De acordo com Passegi (2010), os memoriais proporcionam a oportunidade de os sujeitos escreverem sobre si e ao mesmo tempo refletirem sobre os seus processos formativos.

Participaram da pesquisa cinco discentes do Curso de Licenciatura em Pedagogia do Centro de Formação de Professores (CFP) da Universidade Federal do Recôncavo da Bahia (UFRB). Utilizaramse os sobrenomes desses estudantes para sua identificação, destaca-se que essa opção foi em comum acordo com eles. Desse modo, conforme o Quadro 01, os sujeitos foram identificados por Souza, Cruz, Nascimento, Gonçalves e Mota.

QUADRO 01: IDENTIFICAÇÃO DOS ESTAGIÁRIOS

\begin{tabular}{|c|c|c|c|}
\hline Sobrenome dos estagiários & Idade & Formação do Ensino Médio & Município de origem \\
\hline Souza & 38 & Formação geral & Amargosa - BA \\
\hline Cruz & 23 & Formação geral & Amargosa - BA \\
\hline Nascimento & 19 & Formação geral & Salvador - BA \\
\hline Gonçalves & 26 & Formação geral & Amargosa - BA \\
\hline Mota & 20 & Formação geral & Salvador - BA \\
\hline
\end{tabular}

FONTE: DAS AUTORAS, 2019.

Nos últimos anos percebeu-se que o público ingressante no Curso de Pedagogia é predominantemente jovem. Isso pode ser comprovado a partir da indicação das idades dos discentes dessa pesquisa que, 
apesar de ter uma estudante com 38 anos que concluiu o Ensino Médio em 2000, os demais concluíram essa etapa recentemente. Um fator que merece destaque é que a maioria dos estudantes de Pedagogia da UFRB são mulheres. Nessa turma havia apenas dois homens, sendo um deles colaborador desse estudo. Outra consideração a ser feita é que todos os discentes, conforme o Quadro 01, fizeram a Formação Geral no Ensino Médio e, portanto, a primeira experiência docente ocorre na realização do estágio em Educação Infantil.

No que diz respeito ao local de origem, três estudantes são moradores do município de Amargosa, local da sede do Centro de Formação de Professores (CFP), dois estudantes são oriundos de Salvador, a capital da Bahia, que fica a aproximadamente $250 \mathrm{~km}$ do CFP/UFRB.

Em relação à origem socioeconômica, esses estudantes se reconhecem como sujeitos da classe trabalhadora. Alguns afirmaram que só estão na universidade por conta das políticas afirmativas que permitiram o acesso por meio das cotas raciais, bem como a sua permanência só é possível devido aos Programas de Permanência Qualificada (PPQ) da UFRB, que garante ações articuladas de democratização de ingresso, permanência e pós-permanência no ensino superior nas modalidades de: transporte, moradia, pecuniário à alimentação e pecuniário à moradia. Além disso, dois desses alunos são bolsistas do Programa de Bolsas de Iniciação à Docência (PIBID), um tem bolsa de monitoria de ensino, um faz parte da monitoria de ensino em condição voluntária, e um não dispõe de bolsa, sendo seus gastos custeados por seus pais. A partir das análises dos memoriais desses cinco discentes, faremos uma breve descrição sobre cada um deles, todos são estudantes do curso de Pedagogia do turno matutino do CFP/UFRB.

Souza, participante da pesquisa, tem dois filhos, nasceu em Amargosa - Bahia. Naquele momento tinha 38 anos de idade, filha de pais analfabetos, é a primeira pessoa da família a ingressar numa universidade. Segundo a estudante, ela não frequentou a creche e sua experiência formativa, quando criança, se deu por meio de uma educação moralizante, tanto por seus pais, quanto pela participação na Escola dominical na igreja que frequentava.

Cruz, no momento da participação, tinha 23 anos de idade. Oriunda da zonal rural de Amargosa, onde morou até os 10 anos de idade. Frequentou a escola a partir dos 5 anos em turmas que ela denomina como de alfabetização. De acordo com a discente, ela prometeu a si mesma que "seria a primeira da família a cursar um ensino superior”, e isso em seu memorial é motivo de orgulho.

Nascimento, com 18 anos de idade, nasceu em Salvador - Bahia - e teve que viver a experiência de se mudar para o interior por conta do ingresso no curso superior. A discente descreve em seu memorial que sempre gostou de brincar e que durante a sua infância frequentou uma escola de bairro na capital, Salvador. Para a discente, alguns professores dessa época deixaram boas lembranças.

Gonçalves, tinha 26 anos de idade, nasceu em Amargosa - Bahia. De acordo com os relatos em seu memorial, considera que teve uma infância feliz junto com os seus primos. Seu ingresso na escola formal foi aos 4 anos de idade e, apesar da insegurança nos primeiros dias, teve uma boa adaptação. É a primeira pessoa de sua família a ingressar na Universidade.

Mota, 20 anos de idade, é oriundo da cidade de Salvador e residia em Amargosa desde 2017, quando ingressou na UFRB. De acordo com o memorial desse estudante, ele foi uma criança alegre e teve sua infância marcada pela participação em grupos sociais como a igreja, a escola e a rua. Segundo Mota, ele começou a frequentar a escola com 3 anos de idade e a adaptação nesse espaço foi tranquila.

No próximo subtópico, apresentaremos as análises dos memoriais à luz dos aportes teóricos já utilizados.

\section{DOCÊNCIA NA EDUCAÇ̃̃O INFANTIL: REFLEXÕES DA PRÁTICA}

Para proceder às análises dos memoriais formativos foi preciso elencar categorias que aproximassem as reflexões sobre a docência na Educação Infantil. Nesse sentido, articularam-se quatro categorias que expressaram reflexões dos discentes de Pedagogia da UFRB acerca de suas experiências infantis, bem como os processos formativos no ensino superior. Desse modo, organizaram-se as seguintes categorias: 1) Reflexão sobre as experiências infantis; 2) Aspectos formativos na universidade; 3) Processo formativo no estágio e 4) Reflexões sobre o estágio. 
Sobre a primeira categoria - Reflexão sobre as experiências infantis - buscou-se os elementos comuns nas narrativas dos estudantes acerca das atividades realizadas por eles quando eram crianças. Os discentes reconhecem que os espaços familiares e não escolares de educação são os primeiros contatos de socialização infantil antes da formalização nas creches e pré-escolas. Inclusive, alguns desses discentes não frequentaram a Educação Infantil quando crianças. Nessa categoria foi possível compreender, conforme as formulações teóricas de Ostetto (2008), a importância de se registrar a experiência vivenciada a fim de que ela possa se articular com as ações das práticas pedagógicas. Neste sentido, Gonçalves relata sobre as suas primeiras experiências infantis:

Foi no seio familiar que se deu início as minhas interações. Naquele ambiente eu poderia ser quem eu quisesse, pois ali era respeitado meu espaço enquanto criança que poderia explorar as brincadeiras e imaginação (Memorial de Gonçalves, 2019).

De acordo com a análise dos memoriais, alguns discentes tiveram na igreja sua formação inicial. Para eles, estar inseridos nesse contexto possibilitou uma aproximação com os mais velhos, pois em algumas situações eram as avós que tinham essa tarefa. A figura da avó como cuidadora dessas crianças marca a vida dos sujeitos e isso é muito forte nos relatos. Os discentes Mota e Souza, em seus memoriais, afirmaram que a igreja foi uma das instituições de socialização na infância:

A igreja teve um papel importantíssimo na minha formação pois desde que era pequeno minha vó (Maria Odete) me levava e eu adorava, dançava muito, um ambiente de muita descontração e diversão. Nesse ambiente tive contato com diversas aprendizagens de como se relacionar com as pessoas, respeito ao próximo e aos mais velhos (Memorial de Mota, 2019).

Em alguns dias da semana eu e minha família íamos para a Igreja. Sempre aos domingos pela manhã, tinha a Escola Bíblica Dominical, que era separada por faixa etária de idade. Eu participava da classe das crianças. A professora contava histórias em revistas infantis e após a aula ela perguntava o que havíamos entendido sobre a história, dramatizava histórias para fixar atraindo melhor a nossa atenção, fazia tarefinhas para colorir, colar e brincadeiras referentes ao tema da aula, cantava músicas fazendo coreografias trabalhando a coordenação motora com movimento da música cantada e interação entre as crianças (Memorial de Souza, 2019).

Assim como o discente Mota, encontrou-se em outros memoriais a influência da família, e sobretudo dos avós, na socialização infantil. Tanto no relato acima, como no relato da discente Cruz, percebe-se que a educação dada às crianças exigia o respeito, principalmente, aos mais velhos:

Bom, antes de entrar na escola eu vivia com minha família e a única coisa que eu fazia era brincar. Minha primeira alfabetização veio dos meus avós quando iam fazer plantação, procurar folhas para chás, fazer a colheita da plantação, ir nas casas dos vizinhos e aprender que não poderia desrespeitar as pessoas, em especial os mais velhos, pois eram esses que passavam os ensinamentos e conhecia mais o mundo que nós crianças (Memorial de Cruz, 2019).

De acordo com a discente Cruz, as relações estabelecidas na família permitiam também a presença do brincar, quando afirma: “a única coisa que eu fazia era brincar”. A partir desse relato, é possível compreender que por ser oriunda da zona rural, as brincadeiras emergiam de situações desse contexto.

Minha formação enquanto criança era no convívio com minha família. Eu tenho vários primos com idades semelhantes e na época morávamos todos muito próximos. Então, estávamos estudando em um turno e no outro brincávamos muito. Mesmo morando na zona rural e sendo pobres, nunca foi tirado de mim, nem do meu irmão e dos meus primos o direito de brincar livremente, de brincar sem preocupação, sem imposição do que era brincadeira de menina, nem de menino. Meus primos brincavam de casinha, de profissões e eu e minhas primas subíamos em árvores, brincávamos de bola, de bola de gude sem ouvir que menina é mais fraca que os meninos (Memorial de Cruz, 2019). 
Além das brincadeiras supracitadas, foi comum encontrar nos relatos dos discentes ações de brincadeiras em que eles utilizaram da reprodução interpretativa proposta por Corsaro (2011) em suas brincadeiras de faz de conta, como podemos verificar no trecho abaixo:

As nossas brincadeiras eram de profissões, na qual eu era banqueiro, médico ou psicólogo; bonecas, casinha, escolinha, sendo na maioria das vezes, o professor; baleado e sete pedrinhas, essas brincadeiras geraram em mim diversas aprendizagens como resoluções de contas, problemas, equilíbrio, estratégias. É importantíssimo o brincar na formação infantil para lidar com a vida em sociedade (Memorial de Mota, 2019).

Muitas situações ocorridas com crianças em ambientes não escolares, não são percebidas como parte da construção social do indivíduo, como as brincadeiras. Os aprendizados do dia a dia, as regras e disciplinas, por vezes são banalizadas por serem atividades ordinárias, comuns. Mas essas mesmas aprendizagens tornam-se práticas pedagógicas que auxiliam no desenvolvimento e aprendizagem da criança. Enquanto para muitos o brincar é reduzido apenas a algo comum da criança, a escola de Educação Infantil o vê como processo de construção e interação lúdicas, brincantes e divertidas do sujeito com o meio social. O relato de Souza ajuda a pensar sobre isso quando afirma que:

A brincadeira era bastante divertida, pois tenho irmãos e vizinhos que eram quase todos com idades semelhantes. Explicitamente estávamos vivendo o mesmo período da infância. A minha casa era pequena e então brincávamos na frente de casa; não tínhamos brinquedos comprados em loja e essa falta de ter espaço dentro de casa e do brinquedo comprado não era problema, porque usávamos a imaginação e o movimento do corpo em prol de nossas brincadeiras (Memorial de Souza, 2019).

Percebeu-se, a partir dos relatos dos discentes, que a brincadeira se constitui como um espaço de desenvolvimento e que a ausência de brinquedos industrializados não era motivo para não brincarem. Ao contrário, eles faziam uso da imaginação e do movimento livre para se divertirem.

Ao analisar o memorial de uma das estudantes, identificou-se que o preconceito em relação à educação pública no início dos anos 2000 fez com que sua mãe a matriculasse em uma instituição privada. Sabe-se que foi a partir da promulgação da LDB de 1996 que a Educação Infantil passou a fazer parte da Educação Básica. Desse modo, o período em que a discente Nascimento ingressou na instituição formal de educação era marcado ainda por resquícios de uma visão assistencialista e compensatória para o atendimento de crianças em instituições públicas. O relato de Nascimento demonstra essa ideia.

Minha mãe me matriculou numa escola de bairro por achar que o meio social deste (escola pública), não fosse adequado ao meu desenvolvimento. (Memorial de Nascimento, 2019).

Atualmente, é possível estabelecer um contraponto para o preconceito em relação à educação pública, sobretudo na Educação Infantil, pois a maioria dos espaços nos municípios têm uma infraestrutura adequada e conta, cada vez mais, com profissionais com formação adequada para atender às crianças das creches e pré-escolas públicas.

A partir dessa categoria observou-se, assim como Corsaro (2011), conforme o que ele denomina como reprodução interpretativa, que a construção do saber infantil também se constitui fora do ambiente educacional. E que, ao adentrar a escola, esses saberes devem ser respeitados e considerados pelos profissionais que farão a mediação desses conhecimentos aliando a outros que ocorrerão no contexto escolar da Educação Infantil. Nas palavras do autor, a reprodução interpretativa "abrange os aspectos inovadores e criativos da participação infantil na sociedade” (CORSARO, 2011, p. 31).

No que diz respeito à segunda categoria - Aspectos formativos na universidade - identificou-se situações em que o ingresso na Universidade garantiu outros olhares e a construção de novos saberes acerca da infância e da Educação Infantil. Para esses jovens que agora cursam o Ensino Superior, a universidade possibilitou uma formação ampliada. Nem sempre a escolha por essa profissão é um desejo individual. Em algumas situações eles são incentivados pela família. Isso pode ser observado no relato de Nascimento que diz: 
Decidi cursar Pedagogia e me aventurar em meio ao conhecimento devido ao incentivo da família e da escola. Ao ingressar fui percebendo que mesmo "caindo de paraquedas" nesse curso, os assuntos abordados por eles eram de meu interesse, até então as matérias abordaram assuntos sociais, de luta e militância (Memorial de Nascimento, 2019).

Em outras narrativas, a escolha surge por identificação com a área:

Escolhi o curso de Pedagogia por me identificar com a área e que tenho vontade de atuar como uma futura docente da Educação Infantil (Memorial de Souza, 2019).

É interessante observar que há um reconhecimento da necessidade de reivindicar espaços de diálogos e lutas coletivas na universidade. Apesar de informar que já havia passado por outras experiências formativas, Mota afirma que:

Ao ingressar na universidade eu pude ter contato com outro mundo, mas não completamente diferente das minhas vivências anteriores. Porém acredito que a universidade deveria ser um espaço de mais lutas, diálogos, eventos e a UFRB deixa muito a desejar nessas questões. Estou fazendo o máximo para tentar movimentar juntamente com outros amigos (Memorial de Mota, 2019).

Foi gratificante desenvolver esse trabalho com os memoriais, uma vez que foi possível identificar nesse processo formativo o orgulho em ser o primeiro membro da família a cursar o ensino superior. Desse modo, reafirma-se aqui a importância do processo de interiorização do conhecimento a partir da expansão das redes federais de ensino superior, como demonstra o relato de Souza:

Em 2017 eu ingressei na universidade e estou no terceiro semestre de Pedagogia, e cada dia eu aprendo mais um pouco, e me sinto bem nesse ambiente que é a universidade. Eu sou a primeira dos meus seis irmãos a cursar universidade é um sonho a ser realizado na minha família (Souza, 2019).

De acordo com o relato da discente Souza, vê-se a importância dessa expansão na possibilidade de influenciar a outras pessoas da classe trabalhadora a estar dentro de uma universidade e se reconhecer nesse espaço, com o intuito de ingressar em um curso superior viabilizando a ascensão social.

Em relação à terceira categoria - Processo formativo no estágio - buscou-se compreender, a partir das narrativas dos sujeitos, como o estágio tem colaborado para a inserção na Educação Infantil, possível lócus de trabalho desses discentes uma vez que, de acordo com Barbosa (2009), as diversas linguagens expressivas compõem a formação dos sujeitos. A discente Nascimento explica, em seu relato, como as transformações sociais contribuíram para possibilitar que as crianças pudessem assumir o protagonismo com embasamento teórico para explicar:

As relações crianças/professores sofreram mudanças na sociedade, também mudaram o sentido valorizando os relatos e linguagens da criança como protagonista e interlocutora com a participação do professor. As crianças podem produzir conhecimento e passá-los, reforçando sua comunicação nas relações entre o professor como mediador do conhecimento entre crianças e crianças (Memorial de Nascimento, 2019).

Para o estagiário que vivenciou todas essas experiências e entende todo esse movimento como parte essencial da vida infantil, percebe-se que trabalhar com essa faixa etária requer sensibilidade e atenção, pois as crianças pequenas nos surpreendem a cada ação, gestos, falas e histórias. O discente Mota traz essas descobertas em seu memorial:

A visão que tinha sobre a creche, na minha concepção anterior, era um espaço para o cuidado e supervisão da criança, mas percebi que é mais do que isso, um ambiente educacional, que pode ser uma base muito forte e importante para o desenvolvimento das crianças (Memorial de Mota, 2019). 
Sobre as atividades com os brinquedos e brincadeiras alguns discentes afirmaram também que modificaram o seu olhar para as ações cotidianas nas creches e pré-escolas, como podemos ver no relato a seguir:

Hoje, a experiência de estágio só fez reforçar a importância da brincadeira para o desenvolvimento da criança e é notório o quão importante é a inserção dessas crianças nas escolas de Educação Infantil (Memorial de Gonçalves, 2019).

A respeito da relação interpessoal entre os sujeitos que compõe a Educação Infantil, Cruz relata que:

Vendo as relações crianças/professores, crianças/crianças, foi possível evidenciar a cultura da criança, como ela deve ser respeitada e valorizada no espaço que foi pensado para ela. As brincadeiras, os brinquedos, as curiosidades, as observações, a mediação com o mundo social e afetivo respeitando as especificidades, são as características pertinentes à fase e são os elementos que constituem essa cultura infantil (Memorial de Cruz, 2019).

Desse modo, foi possível compreender, a partir dos relatos dos alunos, que o processo formativo dos discentes a partir da realização do estágio colaborou para a identificação de necessidades das crianças para compor o planejamento, como se percebe abaixo:

As crianças precisam de estímulos e todos os recursos utilizados na semana da regência foi pensado na perspectiva de estimular ainda mais a curiosidade, o movimento, a interação, a comunicação, a percepção, autonomia das crianças (Memorial de Souza, 2019).

Essa compreensão por parte dos estagiários de que os sujeitos da Educação Infantil necessitam de um trabalho articulado e mediado, sejam por adultos ou pelas próprias crianças, só foi possível porque eles se voltaram para a investigação do universo infantil (ROCHA; OSTETTO, 2008). Apesar de o estágio no Centro de Formação de Professores ter como base de sua organização a superação da prática como imitação de modelo, ainda se tem a percepção de que a construção de saberes depende das experiências que eles tiveram com outros professores. Vejamos o que a discente Gonçalves nos diz no relato:

Sempre me questiono que tipo de educadora que serei, algo que muito me preocupa, pois considero que o docente tem papel crucial na vida e na formação dos seus alunos. Durante meu estágio busquei um pouco das práticas dos professores que eu tive na minha formação, os que me marcaram de alguma forma e tentei inserir as ações deles em minha prática (Memorial de Gonçalves, 2019).

Pimenta e Lima (2005-2006) afirmam que aos estagiários deve ser proposta uma práxis a partir da qual ocorra uma "atitude investigativa, que envolve a reflexão e a intervenção na vida da escola, dos professores, dos alunos e da sociedade” (p. 3). Por meio desse relato foi possível perceber como a formação docente não depende unicamente das teorias estudadas na universidade, mas também dos referenciais obtidos em seu processo formativo na educação básica. A partir dessas experiências é possível avaliar as metodologias para serem adequadas ao contexto das práticas educacionais aliado com as teorias, as quais refletem na formação de sua identidade, perpetuando em suas práticas, independente dos embasamentos ocorridos no espaço acadêmico.

A quarta categoria - Reflexões sobre o estágio - apresenta, a partir das considerações das estudantes, situações de aprendizagem durante esse processo formativo. Nessa categoria, discutiram-se também as mudanças de postura frente ao novo campo de atuação, ainda que seja como estagiário.

A capacidade e a sensibilidade do estagiário em olhar para a criança e ver para além do que está a sua frente, também esteve presente nos relatos. Em seu memorial, Mota afirma que:

O estágio foi enriquecedor em diversos aspectos em minha vida: para minha base enquanto profissional e para a minha conscientização humana. As crianças têm um potencial grandioso que muitas vezes não é potencializado e valorizado. É necessária uma atualização das práticas da sociedade para com as crianças (Memorial de Mota, 2019). 
Esse reconhecimento das crianças como sujeitos potentes e protagonistas também aparece no estudo de Rocha, Girardi e Buss-Simão (2014), quando as autoras dizem que a uniformização das ações deixa de respeitar os direitos da criança. Desse modo, faz-se necessário planejar as atividades com a ideia de que as crianças são múltiplas em todas as dimensões.

As mudanças nas escolhas dos discentes iniciaram a partir da confrontação com o futuro lócus de atuação, como se percebe no relato de Gonçalves e Nascimento:

Comecei o curso sem saber direito se era realmente o que queria fazer, pois minha escolha havia sido por ser um curso ao qual não precisaria sair da minha cidade. Porém, já nas primeiras aulas comecei a me encantar pela docência e após o estágio posso dizer que a docência é desafiadora e apaixonante (Memorial de Gonçalves, 2019).

As experiências da creche foram muito gratificantes, pois tive a oportunidade de reviver alguns momentos, que me remeteram a canções infantis da minha infância (Memorial de Nascimento, 2019).

Lembrar da sua própria infância a partir da evocação de música e de histórias também constitui mobilização de saberes apreendidos em outros tempos e espaços. Por outro lado, há os discentes que consideram que apesar de o estágio ser desafiador ele também foi gratificante. Os relatos abaixo comprovam isso:

Refletindo sobre meu estágio considero que ainda há muita coisa para aprender se tratando de educação Infantil. Porém, analiso que essa prática contribuiu muito para minha formação e que de fato a docência tem um misto de desafio e paixão nos quais você é desafiada a todo o momento, mas que no final é recompensada (Memorial de Gonçalves, 2019).

E toda essa colaboração, a interação de todas as professoras e assistentes da creche, me fez entender que a profissão docente não é individual, mas conjunta, independentemente da posição em que elas ocupem e me identifiquei ainda mais com o curso de Pedagogia, pois acredito que sozinho ninguém consegue ir muito longe (Memorial de Cruz, 2019).

Gonçalves demonstrou em seu memorial uma escrita refletida sobre a utilização das brincadeiras para o desenvolvimento integral das crianças. Para ela, essa aprendizagem só foi possível pela oportunidade de estagiar numa instituição de Educação Infantil em que o brincar se faz presente, como exposto abaixo:

Hoje consigo observar a importância desses momentos de brincadeiras. Elas foram peças essenciais para o meu desenvolvimento e interação. Acredito que mesmo sem ter noção do quão importante era essa fase para meu desenvolvimento, minha família contribuiu de maneira muito significativa para que isso ocorresse (Memorial de Gonçalves, 2019).

A partir do estágio na Educação Infantil, os futuros docentes descontroem a ideia, legitimada e perpetuada por anos, de que o professor dessa faixa etária é visto apenas como um cuidador. Têm-se grandes avanços em relação a esses paradigmas, mas ainda assim deve haver um tensionamento, como afirma Drago e Filho (2018, p. 15), “a educação Infantil precisa possuir um caráter educativo que vença essas barreiras históricas de discriminação e preconceito em relação à infância, escolas infantis e professores dessas escolas”. Sobre esse aspecto, Souza apresenta em seu memorial:

Eu vivi na prática como as crianças são extremamente inteligentes, criativas e que não devemos de forma alguma desdenhá-las, pois conviver com elas é ter o olhar observador para cada detalhe, atender cada um em sua especificidade, procurar entender e compreender a dinâmica de trabalhar com pessoas tão pequenas e com sabedorias gigantescas (Memorial de Souza, 2019).

As vivências obtidas por meio do estágio proporcionaram, segundo alguns discentes, o reconhecimento de uma ação firmada na práxis. A discente Cruz afirma que:

Quanto à minha relação com as crianças, foi um verdadeiro aprendizado de que nada sei sobre elas. Quando tudo parece resolvido e solucionado aparece mais surpresas, enigmas, perguntas, respostas para questões que deixam qualquer adulto perplexo. As crianças são extremamente 
criativas, inteligentes e de forma nenhuma devemos subestimá-las. Conviver com elas, observando toda a dinâmica, todas as especificidades, ficar atentos aos detalhes e as coisas que são passadas despercebidas, normalmente por adultos, é impressionante. É como se elas fossem os professores dando aula de humanidade e trabalhar com eles exige profissionais que além da formação, tenham sensibilidade para aproveitar e manter enraizadas essas características nas crianças (Memorial de Cruz, 2019).

Drago e Filho (2018, p. 23) consideram que “[...] o processo de formação docente para a Educação Infantil tem no estágio supervisionado curricular uma ponte para que o aluno se envolva concretamente, de modo crítico e reflexivo, com temáticas que ele pode ter visualizado de forma teórica em seu processo formativo". Compreendemos que é por meio dessas percepções que os discentes vão criando suas concepções de formação e firmando suas identidades sobre como serão suas práticas enquanto educadores.

\section{CONSIDERAÇ̃̃ES FINAIS}

O estágio supervisionado, além de ser uma exigência curricular do curso de Pedagogia, promove a ampliação da visão do discente sobre os processos educativos das crianças da Educação Infantil, permitindo-lhes desenvolver habilidades e percepções acerca do seu futuro ambiente de trabalho.

Desse modo, a partir das análises dos memoriais dos estudantes de Pedagogia foi possível compreender os elementos formativos presentes nas categorias apresentadas. No que se refere à Reflexão sobre as experiências infantis, identificou-se que os discentes trouxeram marcas de suas infâncias para refletir sobre o processo formativo para a futura atuação docente. No que diz respeito aos Aspectos formativos na universidade, percebeu-se a importância da interiorização do ensino superior a fim de garantir o acesso e a permanência dos estudantes da classe trabalhadora na universidade. Em relação ao Processo formativo no estágio, os memoriais apresentaram considerações acerca da prática cotidiana das instituições de Educação Infantil. E, por fim, as Reflexões sobre o estágio nos deram pistas sobre os dilemas e desafios que o estágio apresenta mas, sobretudo, foi possível identificar mudanças de concepções e postura acadêmica ao refletir sobre sua própria experiência.

A partir da inserção no ambiente escolar infantil, os estagiários perceberam como ocorrem as situações cotidianas da prática escolar e conseguiram analisá-las à luz dos referenciais estudados.

Sendo assim, é preciso garantir que todas as ações que permeiam a Educação Infantil estejam pautadas a fim de garantir o desenvolvimento infantil, bem como focar nas construções interativas de maneira a valorizar e reconhecer a importância de promover práticas de educação e cuidado para as crianças dessa faixa etária. Nessa perspectiva, os discentes inseridos nessa primeira experiência compreenderam, por meio do exercício do estágio supervisionado, as especificidades desse campo. Apesar de terem momentos desafiadores e conflitantes, estes foram superados a partir da articulação dos saberes construídos no exercício da docência.

\section{REFERÊNCIAS}

BARBOSA, M. C. S. Ministério Da Educação. Secretaria de Educação Básica Universidade Federal do Rio Grande do Sul. Projeto de cooperação técnica MEC e UFRGS para construção de orientações curriculares para a Educação Infantil. Brasília, 2009.

BRASIL. Lei $\mathbf{n}^{0}$ 9.394, de 20 de dezembro de 1996. Estabelece as Diretrizes e Bases da Educação Nacional. Diário Oficial [da República Federativa do Brasil], Brasília, DF, v. 134, n. 248, 23 dez. 1996.

BUSS-SIMÃO, M.; GRALIK, C.; ROCHA, E. A. C.; STEINBACH, F. "Prepara tudo que nós vamos brincar!”: organizar espaços, possibilitar brincadeiras e experienciar a docência do estágio na educação infantil. Revista Zero a seis. V. 1, n, 29, p. 112-130. Jan-jul 2014. Disponível em: https://periodicos. ufsc.br/index.php/zeroseis/article/view/1980-4512.2014n29p112 Acesso em 10 de mai. de 2019. 
CORSARO, W. A. Sociologia da Infância. 2ª ed. Porto Alegre: Artmed, 2011.

DRAGO, R.; FILHO, J. R. Estágio supervisionado na Educação Infantil: algumas reflexões. In: ZANATA, E. M.; CAPELLINI, V. L. M. F. (Org.) A Prática de Ensino e o Estágio Curricular Supervisionado no Curso de Pedagogia: Desafios e Possibilidades. São Paulo: Ed. Cultura Acadêmica, 2019, p. 14-31.

PASSEGI, M. da C. Narrar é humano! Autobiografar é um processo civilizatório. In: PASSEGI, M. da C.; SILVA, V. B. da (Org.) Invenções de vidas, compreensão de itinerários e alternativas de formação. São Paulo: Cultura Acadêmica, 2010, p. 103-130.

PIMENTA, S. G.; LIMA, M. S. L. Estágio e docência: diferentes concepções. Revista Poíesis. Vol. 3. Número 3 e 4, p.p.5-24, 2005/2006. Disponível em https://www.revistas.ufg.br/poiesis/article/ view/10542/7012 Acesso em 05 de fev. de 2020.

PIMENTA, S. G.; LIMA, M. S. L. Estágio e docência. 5 ed. São Paulo: Cortez, 2010.

ROCHA, E. A. C.; OSTETTO, L. E. O estágio na formação universitária de professores de Educação Infantil. In: SEARA, I. C. et al (Org.). Práticas pedagógicas e estágios: diálogos com a cultura escolar. Florianópolis: Letras contemporâneas, 2008, p. 103-116.

ROCHA, E. A. C.; GIRARDI, L. R.; BUSS-SIMÃO, M. Experimentando a docência com bebês no estágio supervisionado: organizando espaços, brincadeiras e interações. Revista Zero a seis. Florianópolis, v. 16, n. 30, p. 290-303, jul-dez 2014. Disponível em: https://periodicos.ufsc.br/index.php/zeroseis/article/ view/1980-4512.2014n30p90/27693 Acesso em 10 de mai. de 2019.

SANTOS, B. de S. Um discurso sobre as ciências. 5 ed. São Paulo: Cortez, 2008.

SCHALLER, J. Lugares aprendentes e inteligência coletiva: rumo á constituição de um mundo comum. In: PASSEGI, M. da C.; E. C. de S. (Org.) (Auto) Biografia: formação, territórios e saberes, 2008, p. 67-84.

SILVA, I. de O. e. Professoras da Educação Infantil: formação, identidade e profissionalização. Salto para o Futuro, ano 13, n. 10, p. 28-35, 2013. 